\title{
Prognostic significance of red cell distribution width and its relation to increased pulmonary pressure and inflammation in acute heart failure
}

\author{
Ryszard Targoński ${ }^{1}$, Janusz Sadowski ${ }^{1}$, Magdalena Starek-Stelmaszczyk ${ }^{1}$, \\ Radosław Targoński ${ }^{2}$, Andrzej Rynkiewicz ${ }^{1}$ \\ ${ }^{1}$ Department of Cardiology, University of Warmia and Mazury in Olsztyn, Poland \\ ${ }^{2}$ Pomeranian Cardiology Centers, Gdansk, Poland
}

\begin{abstract}
Background: Red cell distribution width (RDW) in acute heart failure (AHF) is accepted as a prognostic indicator with unclear pathophysiological ties. The aim of this study was to evaluate the prognostic value of $R D W$ in $A H F$ patients in relation to clinical and echocardiographic data.

Methods: 170 patients with AHF were retrospectively studied. All patients had laboratory testing and an echocardiogram performed within $24 \mathrm{~h}$ of admission to the Cardiology Department.

Results: During the mean $193 \pm 111$ days of follow-up, 33 patients died. More advanced age, high $R D W$ and low peak early diastolic velocity of the lateral mitral annulus (MVe') were independent predictors of all-cause mortality with hazard ratios of: 1.05 (95\% CI 1.02-1.09), $p<0.005,1.40$ (95\% CI $1.22-1.60), p<0.001$, and 0.77 (95\% CI 0.63-0.93), $p<0.007$, respectively. In a stepwise multiple linear regression model, $R D W$ was correlated with hemoglobin concentration (standardized $\beta=-0.233$, $p<0.001$ ), mean corpuscular volum (standardized $\beta=-0.230, p<0.001$ ), mean corpuscular hemoglobin concentration (standardized $\beta=-0.207, p<0.007$ ), the natural logarithm of $C$-reactive protein $(C R P)$ (standardized $\beta=0.184, p<0.004)$ and tricuspid regurgitation peak gradient $(T R P G)$ values (standardized $\beta=0.179, p<0.006$ ), whereas MVe' was correlated with atrial fibrillation (standardized $\beta=0.269, p<0.001$.

Conclusions: The present data demonstrates a novel relation between higher levels of $R D W$ and elevated $T R P G$ and high sensitivity CRP values in patients with $A H F$. These findings suggest that $R D W$, the most important mortality predictor, is independently associated with elevated pulmonary pressure and systemic inflammation in patients with AHF. Moreover, in AHF patients, more advanced age and decreased MVe' are also independently associated with total mortality risk. (Cardiol J 2020; 27, 4: 394-403)
\end{abstract}

Key words: acute heart failure, red cell distribution width, anemia, MVe', tricuspid regurgitation peak gradient, high sensitivity $\mathrm{C}$-reactive protein

\section{Introduction}

Heart failure (HF) is becoming one of the most important cardiovascular syndromes due to its increasing prevalence, high mortality and increasing cost of care. Despite progress in therapeutic methods for acute heart failure (AHF), it still carries a grim prognosis and that is why searching for reliable predictors of mortality is of utmost importance [1]. Among them, red cell distribution width (RDW) was found to be the cheapest and most widely available indicator. The RDW was established to be a strong predictor of mortality in the general population above 45 years of age [2], as well as during sepsis, trauma and in critically ill patients [3-5]. Several studies confirmed that RDW predicts mortality in acute and chronic heart failure (CHF) [5-9]. It was reported that an increasing

Address for correspondence: Dr. Ryszard Targoński, Department of Cardiology, University of Warmia and Mazury in Olsztyn, ul. Niepodległości 44, 10-045 Olsztyn, Poland, tel/fax: +48 895326202, e-mail: rtarg@op.pl 


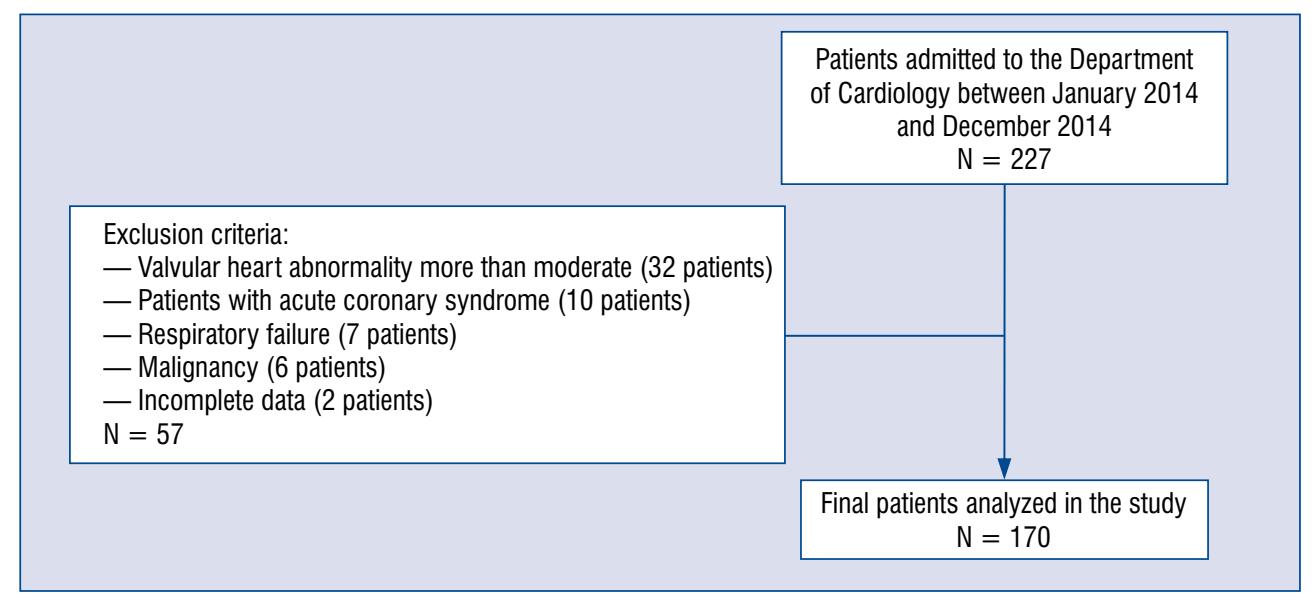

Figure 1. The flow chart of case enrolment of our study according to the inclusive and exclusive criteria.

RDW value is associated with cytokine activation, impaired iron mobilization and decreased hemoglobin $(\mathrm{Hb})$ levels [10-12]. Furthermore, impaired deformability of erythrocytes (RBC) caused by proinflammatory cytokines can also be manifested as increased RDW [4]. The exact mechanism of how elevated RDW is associated with an adverse prognosis has not been entirely elucidated and its relation to clinical findings has not been fully explained. Recently, it was documented that high RDW values were independently associated with increased left ventricular (LV) end diastolic pressure [13]. Data concerning the association of RDW with echocardiographic findings in AHF are scarce and ambiguous $[5,6,14]$. The aim of the present study was to evaluate the mid-term prognostic value of RDW in AHF with regards to clinical and echocardiographic data.

\section{Methods}

The retrospective study included 170 patients chosen from 237 consecutive patients admitted to the hospital due to recent resting dyspnea caused by decompensation of CHF. All patients had N-terminal pro-B-type natriuretic peptide (NT-proBNP) plasma levels that were above 300 units and signs of systolic and/or diastolic LV dysfunction in resting transthoracic echocardiography (ECHO) performed within $24 \mathrm{~h}$ of admission. The following exclusion criteria were applied: age younger than 18 years, valvular heart abnormality higher than moderate, acute coronary syndrome, dyspnea due to concomitant respiratory failure, malignancy and incomplete data (Fig. 1). All patients were treated according to the current guidelines for congestive heart failure (HF). Pharmacotherapy on admission was presented in Tables 1 and 2 . Each patient underwent a standard echocardiogram (Vivid 5, GE Vingmed) using an adaptive 1.3-4.0 MHz transducer. Left atrial diameter (LAd), LV end-diastolic diameter (LVEDD) and right ventricular end-diastolic diameter (RVEDD) were assessed. The tricuspid regurgitation peak gradient (TRPG) was calculated according to the simplified Bernoulli formula, and was measured using a continuous wave Doppler in the modified apical 4-chamber view. The transmitral early diastolic velocity (E) was assessed from the mitral inflow velocity. The LV ejection fraction (LVEF) was measured using the Simpson biplane method. Tissue Doppler myocardial imaging (TDI) was used to assess the peak early diastolic velocity of the lateral mitral annulus (MVe') by placing the Doppler sample volume over the lateral side of the mitral annulus at the posterior leaflet. Venous blood samples were taken for determination of serum creatinine, sodium level, high sensitivity C-reactive protein (hsCRP), D-dimer, NT-proBNP and a complete blood count. Laboratory analysis was performed using a COBAS C-6000 Analyzer (Roche Diagnostic GmGH, Mannheim, Germany). Baseline hematologic analyses were performed using SYSMEX XT 1800i. The reference range for RDW was $11.5-14.5 \%$. The glomerular filtration rate (GFR) was calculated according to the Modification of Diet in Renal Disease (MDRD) formula. Follow-up began on of the day of admission to the Cardiology Department due to AHF. The endpoint of this study was all-cause mortality, including in-hospital and post-discharge deaths. The study protocol was approved by the Warmia 
Table 1. Baseline characteristics and treatments in patients who died or survived.

\begin{tabular}{|c|c|c|c|}
\hline Variable & Survivors $(n=137)$ & Non-survivors ( $n=33$ ) & $\mathbf{P}$ \\
\hline Age [years] & $73.9 \pm 12.5$ & $78.3 \pm 9.4$ & 0.1 \\
\hline Sex, male & $75(54.7 \%)$ & $14(42.42 \%)$ & 0.2 \\
\hline Diabetes mellitus & $44(32.12 \%)$ & $16(48.48 \%)$ & 0.08 \\
\hline Hypertension & $92(67.15 \%)$ & $21(63.64 \%)$ & 0.7 \\
\hline CAD & $20(14.60 \%)$ & $9(27.27 \%)$ & 0.08 \\
\hline COPD & $23(16.79 \%)$ & $7(21.21 \%)$ & 0.6 \\
\hline History of DVT & $9(6.57 \%)$ & $6(18.18 \%)$ & 0.04 \\
\hline Acute infection & $50(36.5 \%)$ & $9(27.27 \%)$ & 0.3 \\
\hline Heart rate $[\mathrm{bpm}]$ & $78.42 \pm 17.03$ & $85.6 \pm 15.89$ & 0.03 \\
\hline BP systolic [mmHg] & $136.8 \pm 26.5$ & $133.3 \pm 21.7$ & 0.5 \\
\hline BP diastolic [mmHg] & $80.8 \pm 15.2$ & $82.0 \pm 14.4$ & 0.7 \\
\hline Weight $[\mathrm{kg}]$ & $83.1 \pm 19.5$ & $77.6 \pm 11.8$ & 0.1 \\
\hline BMI [kg/m²] & $30.9 \pm 6.5$ & $28.3 \pm 4.2$ & 0.03 \\
\hline NT-proBNP [pg/mL] & 2539 [1431-5496] & 4240 [2028-9090] & 0.03 \\
\hline $\mathrm{Hb}[\mathrm{g} / \mathrm{dL}]$ & $12.8 \pm 2.3$ & $11.8 \pm 2.7$ & 0.04 \\
\hline RDW [\%] & $15.0 \pm 1.8$ & $16.9 \pm 2.9$ & 0.00003 \\
\hline $\mathrm{Ht}[\%]$ & $39.07 \pm 6.27$ & $37.03 \pm 7.84$ & 0.1 \\
\hline $\mathrm{MCV}[\mathrm{fL}]$ & $90.78 \pm 6.88$ & $90.66 \pm 9.44$ & 0.9 \\
\hline $\mathrm{MCHC}[\mathrm{g} / \mathrm{dL}]$ & $32.87 \pm 1.69$ & $32.44 \pm 1.46$ & 0.2 \\
\hline Leukocytes [G/mL] & $8.3 \pm 3.3$ & $7.7 \pm 3.2$ & 0.3 \\
\hline $\mathrm{PLT}[\mathrm{G} / \mathrm{mL}]$ & $217.8 \pm 126.9$ & $186.1 \pm 92.3$ & 0.2 \\
\hline $\mathrm{Na}[\mathrm{mmol} / \mathrm{L}]$ & $139.2 \pm 4.3$ & $137.9 \pm 5.1$ & 0.1 \\
\hline Creatinine [mg/dL] & $1.2 \pm 0.4$ & $1.3 \pm 0.6$ & 0.3 \\
\hline eGFR $\left[\mathrm{mL} / \mathrm{min} / 1.73 \mathrm{~m}^{2}\right]$ & $62.5 \pm 26.5$ & $58.5 \pm 23.6$ & 0.4 \\
\hline CRP $[\mathrm{mg} / \mathrm{L}]$ & $3.7[1.5-12.7]$ & $14.0[5.0-34.8]$ & 0.0005 \\
\hline $\mathrm{D}$-dimer $[\mu \mathrm{g} / \mathrm{mL}]$ & $0.9[0.5-1.5]$ & $1.7[0.7-3.1]$ & 0.02 \\
\hline LBBB & $12(8.76 \%)$ & $3(9.09 \%)$ & 1.0 \\
\hline RBBB & $6(4.38 \%)$ & $3(9.09 \%)$ & 0.3 \\
\hline AF & $68(49.64 \%)$ & $16(48.49 \%)$ & 0.91 \\
\hline LAd $[\mathrm{cm}]$ & $4.9 \pm 0.8$ & $4.9 \pm 0.6$ & 0.8 \\
\hline LVEDD [cm] & $5.6 \pm 0.9$ & $5.5 \pm 1.0$ & 0.9 \\
\hline RVEDD [cm] & $3.3 \pm 0.7$ & $3.3 \pm 0.7$ & 0.9 \\
\hline EF [\%] & $43.1 \pm 15.2$ & $41.6 \pm 17.2$ & 0.6 \\
\hline TRPG [mmHg] & $35.9 \pm 13.6$ & $42.2 \pm 14.4$ & 0.02 \\
\hline $\mathrm{E}[\mathrm{cm} / \mathrm{s}]$ & $94.9 \pm 29.4$ & $84.7 \pm 26.6$ & 0.07 \\
\hline $\mathrm{MVe}^{\prime}[\mathrm{cm} / \mathrm{s}]$ & $8.5 \pm 2.6$ & $7.3 \pm 1.7$ & 0.01 \\
\hline $\mathrm{E} / \mathrm{MVe}^{\prime}$ & $12.4 \pm 4.7$ & $12.5 \pm 2.7$ & 0.8 \\
\hline Mitral regurgitation & $24(17.52 \%)$ & $5(15.15 \%)$ & 0.8 \\
\hline ACEI/ARB & $129(94.16 \%)$ & $27(81.82 \%)$ & 0.02 \\
\hline Spironolactone & $74(54.01 \%)$ & $23(69.70 \%)$ & 0.1 \\
\hline Furosemide & $103(75.18 \%)$ & $26(78.79 \%)$ & 0.7 \\
\hline Chlortalidone & $44(32.12 \%)$ & $6(18.18 \%)$ & 0.1 \\
\hline Hydrochlorothiazide & $24(17.52 \%)$ & $5(15.15 \%)$ & 0.8 \\
\hline Oral anticoagulant & $89(64.96 \%)$ & $18(54.55 \%)$ & 0.3 \\
\hline Statins & $76(55.47 \%)$ & $13(39.39 \%)$ & 0.1 \\
\hline Beta-blockers & $118(86.13 \%)$ & $25(75.76 \%)$ & 0.1 \\
\hline
\end{tabular}

Data are shown as mean \pm standard deviation/median [IQR]/patients' number (\%); IQR - range from $1^{\text {st }}$ to $3^{\text {rd }}$ quartile; CAD — coronary artery disease; COPD - chronic obstructive pulmonary disease; DVT - deep vein thrombosis; BP - blood pressure; BMI - body mass index; NT-proBNP - N-terminal pro-B-type natriuretic peptide; Hb - hemoglobin; RDW - red blood cell distribution width; Ht - hematocrit; $\mathrm{MCV}$ - mean corspuscular volume; MCHC - mean corpuscular hemoglobin concentration; PLT - platelet count; eGFR - estimated glomerular filtration rate; CRP — C-reactive protein; LBBB - left bundle branch block; RBBB - right bundle branch block; AF - atrial fibrillation LAd - left atrium diameter; LVEDD - left ventricular end-diastolic diameter; RVEDD - right ventricular end-diastolic diameter; EF - ejection faction; TRPG — tricuspid regurgitation peak gradient; $\mathrm{E}$ - early diastolic mitral inflow velocity; MVe' — peak early diastolic velocity of the faction; TRPG - tricuspid regurgitation peak gradient; $\mathrm{E}$ - early diastolic mitral inflow velocity; MVe - peak early d
mitral annulus lateral portion; ACEI - angiotensin converting enzyme inhibitor; ARB - angiotensin receptor blocker 
Table 2. Total mortality in relation to clinical measures.

\begin{tabular}{|c|c|c|c|c|c|c|c|c|}
\hline \multirow{3}{*}{$\begin{array}{l}\text { Variable } \\
\text { Age [years] }\end{array}$} & \multicolumn{4}{|c|}{$\begin{array}{l}\text { Univariate Cox proportional } \\
\text { survival analysis }(n=170)\end{array}$} & \multicolumn{4}{|c|}{$\begin{array}{l}\text { Multivariate Cox proportional } \\
\text { survival analysis }(\mathrm{n}=170)\end{array}$} \\
\hline & \multirow{2}{*}{$\begin{array}{c}\text { HR } \\
1.034\end{array}$} & \multicolumn{2}{|c|}{$95 \% \mathrm{Cl}$} & \multirow{2}{*}{$\begin{array}{c}\mathbf{P} \\
0.05\end{array}$} & \multirow{2}{*}{$\begin{array}{c}\text { HR } \\
1.050\end{array}$} & \multicolumn{2}{|c|}{$95 \% \mathrm{Cl}$} & \multirow{2}{*}{$\begin{array}{c}\mathbf{P} \\
0.005\end{array}$} \\
\hline & & 1.000 & 1.070 & & & 1.015 & 1.087 & \\
\hline Sex, male & 0.658 & 0.330 & 1.313 & 0.2 & & & & \\
\hline Diabetes mellitus & 1.698 & 0.858 & 3.361 & 0.1 & & & & \\
\hline Hypertension & 0.834 & 0.410 & 1.696 & 0.6 & & & & \\
\hline CAD & 2.169 & 0.895 & 5.257 & 0.09 & & & & \\
\hline COPD & 1.328 & 0.576 & 3.062 & 0.5 & & & & \\
\hline History of DVT & 2.169 & 0.895 & 5.257 & 0.09 & & & & \\
\hline Acute infection & 1.420 & 0.660 & 3.055 & 0.4 & & & & \\
\hline Heart rate [bmp] & 1.022 & 1.006 & 1.038 & 0.007 & & & & \\
\hline Systolic BP [mmHg] & 0.978 & 1.007 & 0.317 & 1.0 & & & & \\
\hline Diastolic BP [mmHg] & 1.003 & 0.980 & 1.026 & 0.8 & & & & \\
\hline Weight $[\mathrm{kg}]$ & 0.983 & 0.964 & 1.003 & 0.1 & & & & \\
\hline BMI $\left[\mathrm{kg} / \mathrm{m}^{2}\right]$ & 0.934 & 0.882 & 0.989 & 0.02 & & & & \\
\hline NT-proBNP [pg/mL] & 1.629 & 1.161 & 2.285 & 0.005 & & & & \\
\hline $\mathrm{Hb}[\mathrm{g} / \mathrm{dL}]$ & 0.880 & 0.771 & 1.005 & 0.06 & & & & \\
\hline RDW [\%] & 1.348 & 1.194 & 1.522 & $<0.001$ & 1.396 & 1.221 & 1.596 & $<0.001$ \\
\hline $\mathrm{Ht}[\%]$ & 0.966 & 0.919 & 1.016 & 0.2 & & & & \\
\hline $\operatorname{MCV}[\mathrm{fL}]$ & 0.991 & 0.947 & 1.036 & 0.7 & & & & \\
\hline $\mathrm{MCHC}[\mathrm{g} / \mathrm{dL}]$ & 0.855 & 0.700 & 1.043 & 0.1 & & & & \\
\hline Leukocytes [G/mL] & 1.030 & 0.895 & 1.185 & 0.7 & & & & \\
\hline PLT [G/mL] & 0.997 & 0.992 & 1.001 & 0.2 & & & & \\
\hline $\mathrm{Na}[\mathrm{mmol} / \mathrm{L}]$ & 0.962 & 0.894 & 1.034 & 0.3 & & & & \\
\hline Creatinine [mg/dL] & 1.544 & 0.810 & 2.945 & 0.2 & & & & \\
\hline eGFR $\left[\mathrm{mL} / \mathrm{min} / 1.73 \mathrm{~m}^{2}\right]$ & 0.994 & 0.980 & 1.009 & 0.4 & & & & \\
\hline $\mathrm{CRP}[\mathrm{mg} / \mathrm{L}]$ & 1.476 & 1.184 & 1.841 & 0.001 & & & & \\
\hline $\mathrm{D}$-dimer $[\mu \mathrm{g} / \mathrm{mL}]$ & 1.195 & 1.076 & 1.326 & 0.001 & & & & \\
\hline LBBB & 1.074 & 0.328 & 3.520 & 0.9 & & & & \\
\hline RBBB & 2.346 & 0.715 & 7.694 & 0.2 & & & & \\
\hline$A F$ & 0.996 & 0.503 & 1.971 & 1.0 & & & & \\
\hline LAd [cm] & 0.965 & 0.647 & 1.439 & 0.9 & & & & \\
\hline LVEDD [cm] & 0.987 & 0.681 & 1.431 & 0.9 & & & & \\
\hline RVEDD [cm] & 0.881 & 0.532 & 1.459 & 0.6 & & & & \\
\hline EF [\%] & 0.993 & 0.972 & 1.015 & 0.5 & & & & \\
\hline TRPG [mmHg] & 1.023 & 1.001 & 1.046 & 0.04 & & & & \\
\hline $\mathrm{E}[\mathrm{cm} / \mathrm{s}]$ & 0.985 & 0.971 & 0.999 & 0.03 & & & & \\
\hline $\mathrm{MVe}^{\prime}[\mathrm{cm} / \mathrm{s}]$ & 0.846 & 0.746 & 0.958 & 0.009 & 0.767 & 0.632 & 0.931 & 0.007 \\
\hline $\mathrm{E} / \mathrm{MVe}^{\prime}$ & 1.016 & 0.941 & 1.097 & 0.7 & & & & \\
\hline Mitral regurgitation & 0.996 & 0.503 & 1.971 & 1.0 & & & & \\
\hline ACEI/ARB & 0.339 & 0.140 & 0.822 & 0.02 & & & & \\
\hline Spironolactone & 1.614 & 0.768 & 3.395 & 0.2 & & & & \\
\hline Furosemide & 1.156 & 0.502 & 2.664 & 0.7 & & & & \\
\hline Chlortalidone & 0.459 & 0.189 & 1.112 & 0.09 & & & & \\
\hline Hydrochlorothiazide & 1.013 & 0.390 & 2.633 & 1.0 & & & & \\
\hline Oral anticoagulant & 0.670 & 0.338 & 1.330 & 0.3 & & & & \\
\hline Statins & 0.537 & 0.267 & 1.079 & 0.08 & & & & \\
\hline Beta-blockers & 0.468 & 0.211 & 1.040 & 0.06 & & & & \\
\hline
\end{tabular}

$\mathrm{HR}$ - hazard ratio; $\mathrm{Cl}$ - confidential interval. The meaning of other abbreviations are the same as in Table 1. 
and Masuria Medical Chamber Ethics Committee (no. 435/06).

\section{Statistical analysis}

Normally distributed variables were reported as mean and standard deviation. Variables that did not have a normal distribution were reported as median and interquartile range. Depending on the type of distribution of the variables, the groups were compared using the Student $t$ test or the Mann-Whitney test. The $\chi^{2}$ test was used to compare qualitative variables between groups. A value of $p<0.05$ was considered statistically significant.

Variables selected to be tested in multivariate analysis were those with $\mathrm{p}<0.1$ in the univariate model. Multivariate survival analysis was performed using the Cox proportion hazard model to determine which factors were significantly associated with death after adjustment for the other variables. A stepwise selection was done using a $\mathrm{p}$ to remove and a $\mathrm{p}$ to enter into the model $\leq 0.05$ with both prior backward selection after inclusion of all selected variables and then forward selection.

For the receiver operator characteristic (ROC) Youden Index was used to find the optimal cut-off points for the best discrimination of death risk. Kaplan-Meier survival curves analysis for the optimal cut-off point of RDW was created and statistical comparison between survival curves was done using the log-rank test.

Linear regression analysis was used to evaluate association between clinical variables and the most important independent death predictors. Identified variables $(\mathrm{p}<0.1)$ were considered to enter in a stepwise manner to the multivariate linear regression model. The variable retention criterion was set at $\leq 0.05$.

All statistical analysis was performed using STATSTICA 12 software.

\section{Results}

The study included 170 patients (males 47.7\%). The mean observation time was $193 \pm$ \pm 111 days. Within the follow-up period, 33 (19.4\%) patients died.

The baseline characteristics of the survivor and non-survivor groups are presented in Table 1. For survivors, the mean age was $73.9 \pm 12.5$ and for non-survivors the mean age was $78.3 \pm 9.4$ years $(\mathrm{p}=0.1)$. A history of deep vein thrombosis was more frequent in the non-survivors group $(18.2 \%$ vs. $6.6 \%, \mathrm{p}<0.04)$. There was a similar prevalence of reported comorbidities and acute infections in both studied groups. The number of subjects with anemia in survivors and non-survivors in the study group was $56(40.88 \%)$ and 19 $(57.58 \%)$, respectively $(\mathrm{p}=0.08)$. After exclusion of anemic subjects, the median value of RDW in survivors and non-survivors was $14.4(13.8-15.5)$ and 15.7 (14.6-17.30), respectively $(\mathrm{p}=0.03)$. Treatment with angiotensin-converting enzyme inhibitor/angiotensin receptor blocker (ACEI/ARB) was significantly more frequent in the survivors group. Biochemical and clinical analyses revealed significantly higher concentration of NT-proBNP, CRP, D-dimer, and higher RDW and TRPG values in non-survivors (Table 1). In the non-survivors group, significantly lower $\mathrm{Hb}$ concentration and diminished MVe' values were found.

The univariate relative risk of mortality in relation to clinical variables is listed in Table 2 . The presence of advanced age, higher values of NT-proBNP, CRP, D-dimer, RDW, TRPG, and lower values of mitral $\mathrm{E}$ and MVe' were related to total mortality.

The multivariate relative risk of mortality in relation to clinical variables is presented in Table 2 . Advanced age, increased RDW value and decreased lateral MVe' velocity were retained as independent predictors for all-cause mortality with hazard ratios of 1.05 (95\% CI 1.02-1.09), p < 0.005, 1.40 (95\% CI 1.22-1.60), $\mathrm{p}<0.001$, and 0.77 (95\% CI $0.63-0.93), \mathrm{p}<0.007$, respectively.

In the univariate linear regression analysis, RDW was positively correlated with the natural logarithm of CRP (LnCRP), TRPG, NT-proBNP and RVEDD. Negative RDW correlation was found with $\mathrm{Hb}$, hematocrit, mean corpuscular volume (MCV) and mean corpuscular hemoglobin concentration (MCHC) values. In the stepwise multiple linear regression model, RDW was correlated with $\mathrm{Hb}$, MCV, MCHC, LnCRP and TRPG values (Table 3).

In the stepwise multiple linear regression model, MVe' was correlated with the presence of atrial fibrillation (AF) (standardized $\beta=0.269$, $\mathrm{p}<0.001)$.

In the whole study group the ROC curve analysis for RDW revealed that area under curve (AUC) was 0.72 (95\% CI 0.62-0.82; p < 0.0001). The ROC curve analysis in the subgroup without anemia revealed AUC of 0.69 (95\% CI $0.53-0.84$; $\mathrm{p}<0.02$ ). RDW value $\geq 14.6$ was found to be the optimal cut-off point for the discrimination of death risk. The same value of optimal cut-off point was found for non-anemic patients. RDW value $\geq 14.6$ in the whole study group was found to have sensitivity and specificity of $86 \%$ and $51 \%$ and for non-anemic patients $78.6 \%$ and $56.0 \%$, respectively. 
Table 3. Univariate and multivariate analysis of association of patient characteristics with RDW.

\begin{tabular}{|c|c|c|c|c|c|c|}
\hline \multirow[t]{2}{*}{ Variable } & \multicolumn{3}{|c|}{ Univariate linear regression analysis } & \multicolumn{3}{|c|}{ Multivariate linear regression analysis } \\
\hline & $\beta$ unstandarised \pm SD & $\beta$ standarised & $\mathbf{P}$ & $\beta$ unstandarised \pm SD & $\beta$ standarised & $\mathbf{P}$ \\
\hline Age [years] & $-0.014 \pm 0.014$ & -0.078 & 0.3 & & & \\
\hline Sex, male & $0.175 \pm 0.168$ & 0.080 & 0.3 & & & \\
\hline Diabetes mellitus & $0.140 \pm 0.175$ & 0.062 & 0.4 & & & \\
\hline Hypertension & $-0.289 \pm 0.175$ & -0.126 & 0.1 & & & \\
\hline CAD & $0.275 \pm 0.224$ & 0.095 & 0.2 & & & \\
\hline COPD & $-0.348 \pm 0.217$ & -0.123 & 0.1 & & & \\
\hline DVT history & $0.001 \pm 0.265$ & 0 & 1.0 & & & \\
\hline Acute infection & $-0.064 \pm 0.177$ & -0.028 & 0.7 & & & \\
\hline Heart rate $[\mathrm{bpm}]$ & $0.018 \pm 0.010$ & 0.143 & 0.06 & & & \\
\hline Systolic BP [mmHg] & $-0.0003 \pm 0.007$ & -0.003 & 1.0 & & & \\
\hline Diastolic BP [mmHg] & $-0.006 \pm 0.011$ & -0.038 & 0.6 & & & \\
\hline Weight [kg] & $-0.002 \pm 0.009$ & -0.016 & 0.8 & & & \\
\hline BMI $\left[\mathrm{kg} / \mathrm{m}^{2}\right]$ & $-0.028 \pm 0.027$ & -0.079 & 0.3 & & & \\
\hline NT-proBNP [pg/mL] & $0.000 \pm 0.000$ & 0.181 & 0.02 & & & \\
\hline $\mathrm{Hb}[\mathrm{g} / \mathrm{dL}]$ & $-0.356 \pm 0.065$ & -0.392 & $<0.001$ & $-0.212 \pm 0.065$ & -0.233 & 0.001 \\
\hline $\mathrm{Ht}[\%]$ & $-0.108 \pm 0.024$ & -0.331 & $<0.001$ & & & \\
\hline $\mathrm{MCV}[\mathrm{fL}]$ & $-0.108 \pm 0.021$ & -0.369 & $<0.001$ & $-0.067 \pm 0.02$ & -0.23 & 0.001 \\
\hline $\mathrm{MCHC}[\mathrm{g} / \mathrm{dL}]$ & $-0.557 \pm 0.092$ & -0.425 & $<0.001$ & $-0.271 \pm 0.099$ & -0.207 & 0.007 \\
\hline Leukocytes [G/mL] & $-0.042 \pm 0.051$ & -0.064 & 0.4 & & & \\
\hline PLT [G/mL] & $0.002 \pm 0.001$ & 0.094 & 0.2 & & & \\
\hline $\mathrm{Na}[\mathrm{mmol} / \mathrm{L}]$ & $-0.053 \pm 0.037$ & -0.109 & 0.2 & & & \\
\hline Creatinine [mg/dL] & $0.572 \pm 0.347$ & 0.127 & 0.1 & & & \\
\hline eGFR $\left[\mathrm{mL} / \mathrm{min} / 1.73 \mathrm{~m}^{2}\right]$ & $0.004 \pm 0.006$ & 0.051 & 0.5 & & & \\
\hline LnCRP $[\mathrm{mg} / \mathrm{L}]$ & $0.330 \pm 0.109$ & 0.229 & 0.003 & $0.266 \pm 0.092$ & 0.184 & 0.004 \\
\hline $\mathrm{D}$-dimer $[\mu \mathrm{g} / \mathrm{mL}]$ & $0.160 \pm 0.085$ & 0.143 & 0.06 & & & \\
\hline LBBB & $-0.267 \pm 0.297$ & -0.069 & 0.4 & & & \\
\hline RBBB & $0.603 \pm 0.374$ & 0.123 & 0.1 & & & \\
\hline AF & $0.142 \pm 0.169$ & 0.065 & 0.4 & & & \\
\hline LAd [cm] & $0.335 \pm 0.209$ & 0.123 & 0.1 & & & \\
\hline LVEDD [cm] & $0.167 \pm 0.179$ & 0.072 & 0.4 & & & \\
\hline RVEDD $[\mathrm{cm}]$ & $0.523 \pm 0.238$ & 0.168 & 0.03 & & & \\
\hline EF [\%] & $-0.010 \pm 0.011$ & -0.073 & 0.3 & & & \\
\hline TRPG [mmHg] & $0.035 \pm 0.012$ & 0.227 & 0.003 & $0.028 \pm 0.01$ & 0.179 & 0.006 \\
\hline $\mathrm{E}[\mathrm{cm} / \mathrm{s}]$ & $0.004 \pm 0.006$ & 0.057 & 0.5 & & & \\
\hline $\mathrm{MVe}^{\prime}[\mathrm{cm} / \mathrm{s}]$ & $0.003 \pm 0.003$ & 0.078 & 0.3 & & & \\
\hline $\mathrm{E} / \mathrm{MVe}^{\prime}$ & $0.051 \pm 0.039$ & 0.101 & 0.2 & & & \\
\hline Mitral regurgitation & $0.286 \pm 0.223$ & 0.098 & 0.2 & & & \\
\hline
\end{tabular}

SD - standard deviation; the meaning of all abbreviations are the same as in Table 1 and Table 2.

When Kaplan-Meier survival curves for 1-year mortality were constructed, patients with RDW $\geq 14.6$ had a 1 -year cumulative survival probability of $65 \%$ compared with $92 \%$ for those with
RDW $<14.6$ ( $\mathrm{p}<0.001$ in log-rank test) (Fig. 2) Number of patients at risk in the group assessed with RDW $\geq 14.6$ was 97 and in the group with RDW $<14.6$ was 73 subjects. 


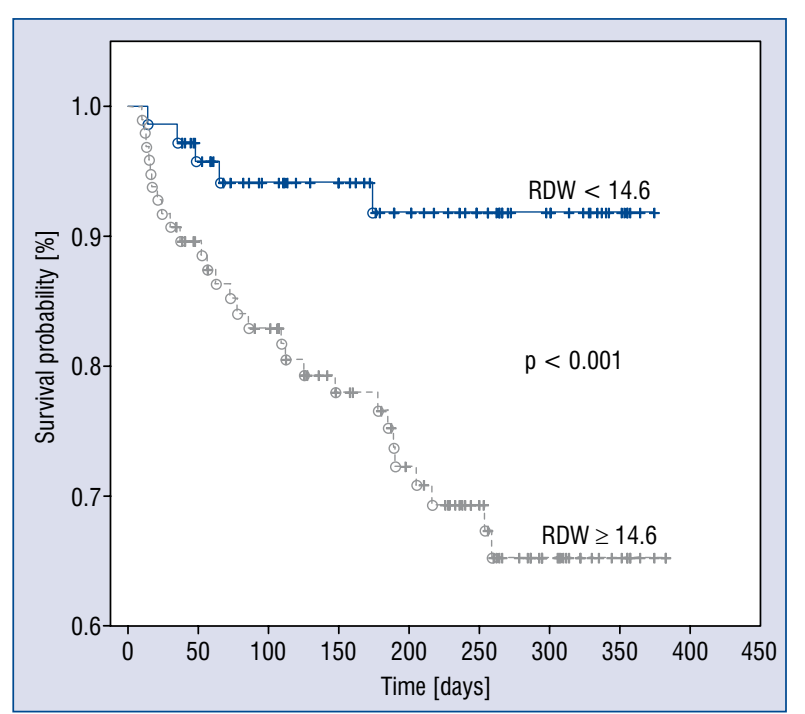

Figure 2. Kaplan-Meier survival curves for total mortality in 170 patients with acute heart failure with red cell distribution width $(\mathrm{RDW}) \geq 14.6(\mathrm{n}=97)$ and RDW $<14.6(\mathrm{n}=73)$.

\section{Discussion}

Elevated RDW on admission is the most powerful independent predictor of all-cause mortality in AHF patients. A 1\% RDW increase predicted an almost $40 \%$ increase in total mortality risk, which is consistent with previously reported data in $\mathrm{AHF}$ $[6,7,15-17]$.

There are numerous reasons for RDW elevation under different clinical conditions. Traditionally, an isolated rise in RDW is the first abnormality seen in early iron deficiency and coupled with a low MCV is regarded as being diagnostic of absolute iron deficiency [16, 17]. Hemoglobin concentration and automatically measured red cell indices are considered sensitive indicators of systemic iron status [18]. It was found that iron deficiency is an ominous finding in CHF [17]. As the deficit worsens, the $\mathrm{MCHC}$ falls with a further reduction in $\mathrm{MCV}$. In the present study, increased RDW was independently correlated with a low $\mathrm{Hb}$ level, as well as decreased MCV and MCHC values. Similar correlations have been described by other authors $[8,19]$ in AHF patients. In a recent study by Senthong et al. [13] this correlation was observed in patients who underwent elective coronary angiography. Moreover, van Kimmenade et al. [8] found no correlation between increased RDW and serum iron, TIBC, serum transferin saturation and ferritin level. Allen et al. [10] demonstrated similar findings in CHF patients. They additionally found a correlation between elevated RDW and high eyrthropoetin levels, normal iron binding capacity and ferritin levels. All results are consistent with a state of impaired iron mobilization and the inhibition of erythropoietin-induced erythrocyte maturation, the hallmark of anemia in chronic diseases [20]. There is an increasing recognition that in the AHF population, the ability to mobilize and use existing iron stores may be impaired even in the setting of adequate overall total body iron [21]. This is sometimes referred to as "reticuloendothelial block", and it is mediated in part by the overexpression of hepcidin; a peptide hormone secreted by the liver which is upregulated by inflammation and acts as a regulator of human iron metabolism [10, 22].

In the entire study group, an association between lower MCV, MCHC and $\mathrm{Hb}$ concentration with higher RDW may indicate an underlying iron deficiency, but it cannot be excluded that the RDW value is also modified by erythrocyte destruction and ineffective iron utilization for red cell production [23]. In rodent models of sepsis, decreases in $\mathrm{Hb}$ content and erythrocyte deformability resulting in RDW elevation was shown to be most profound in the second-oldest subpopulation of cells accounting for $20 \%$ of total circulating erythrocytes [24]. On the other hand, it was demonstrated that RDW elevation is caused by a rise of immature erythrocyte forms [11].

In the present study group, increased RDW was independently positively correlated with hsCRP level. Lippi et al. [23] demonstrated a similar correlation in an unselected population between high RDW and elevated CRP concentration. It was reported that inflammation alters erythropoiesis by direct myelosuppression of erythroid precursors, promotion of red cell apoptosis, reduction of erythropoietin production, reduced iron bioavailability, and erythropoietin resistance in erythroid precursor cell lines. CRP contributes to stimulating the secretion of cytokines and tissue factor, it also induces the expression of adhesion molecules from endothelial cells [25]. Inflammatory cytokines also suppress erythrocyte maturation, allowing newer, larger reticulocytes to enter the circulation and skew the RDW distribution [4]. An inverse correlation between RDW and $\mathrm{MCV}, \mathrm{MCHC}$ and $\mathrm{Hb}$ values indicate that proliferation and new erythrocytes entering into circulation are less important than erythrocyte destruction in the study group. The median hsCRP value in the non-survivors group was $14.0(5.0-34.8) \mathrm{mg} / \mathrm{L}$. The elevation of hsCRP above $10 \mathrm{mg} / \mathrm{L}$ should be evaluated for noncardiovascular etiologies, most likely resulting from an infection [26]. The prevalence of acute 
infection was similar for both the survivors and non-survivors group. Therefore, it seems that in AHF patients studied, destruction of erythrocytes is associated not only with HF related vascular inflammation but probably also with severity of the superimposed infection.

The inflammatory process, particularly accompanying HF, is an important pro-thrombotic factor. In the present study, D-dimer concentration was significantly higher in the non-survivors group in univariate regression analysis and a significant positive correlation between $\mathrm{D}$-dimer and RDW was observed. No patients had clinical symptoms of recent deep vein thrombosis or acute coronary syndrome, so activated fibrinolysis is rather connected with other vascular territories. Itani et al. [7] found that a higher DIC score was independently associated with risk of death in AHF patients. Interestingly, it was reported that in patients with hypoxemia and pulmonary hypertension due to $\mathrm{HF}$, endothelial dysfunction and ongoing intravascular coagulation was associated with the occurrence of ischaemic and thrombotic pulmonary events [27]. In a mixed etiology pulmonary hypertension population, it was demonstrated that elevated RDW levels were inversely correlated with $\mathrm{Hb}$ and $\mathrm{MCV}$ values which is in line with the present results [12]. Tandon et al. [28] described extensive thrombotic pulmonary vascular changes at various stages of organization with pulmonary iron deposits seen in $70 \%$ of cases in patients with severe pulmonary hypertension due to isolated mitral stenosis. Similar abnormalities were described in HF and pulmonary hypertension [29].

According to available research, the current study provides the first data evaluating the relationship between the RDW and TRPG values in AHF. An independent direct positive correlation between RDW with TRPG values in the present study group may indicate the role of elevated pulmonary artery pressure on the modification of RDW values. It has been proven that blood stasis, due to low cardiac output, passive vascular distension, and systemic inflammation leads to endothelial dysfunction by means of neurohormonal activation [30]. Costello et al. [31] have described disruption of some or all layers of the alveolar-capillary unit by elevated capillary hydrostatic pressures, a phenomenon they referred to as pulmonary capillary stress failure. When all of the layers are disrupted, RBCs may be seen traversing the alveolarcapillary membrane. It was found that $\mathrm{RBC}$ destruction releases free $\mathrm{Hb}$, and these react with nitric oxide to form inactive nitrate and methemoglobin, thus leading to endothelial dysfunction [32]. Recently in a murine model of hemolysis, a significant reduction in nitric oxide bioavailability due to free $\mathrm{Hb}$ was shown to be accompanied by platelet activation and the activation of a coagulation pathway resulting in thrombosis, pulmonary hypertension, right ventricular failure and eventually death [32]. The impact of increased pulmonary pressure on vascular endothelial cells in AHF may lead to erythrocyte damage and serve as an important modifier of the $\mathrm{RDW}$. Free $\mathrm{Hb}$ leads to further microcirculation damage and creation of a self-perpetuating vicious circle. It has been demonstrated that unfractionated heparin treatment in cardio-renal syndrome and peripheral vein thrombosis without pulmonary embolism resulted in lowering pulmonary arterial hypertension and increased plasma anticoagulants indicating the thrombotic nature of the underlying pathology which plays an important role in pulmonary circulation of AHF patients [33].

Results herein demonstrate that decreased MVe', unlike LVEF and other echocardiographic data including the $\mathrm{E} / \mathrm{MVe}$ ' ratio in $\mathrm{AHF}$ patients, independently predicts risk of death. Gandhi et al. [34] first described that the impairment of diastolic dysfunction in patients with sinus rhythm is associated with the development of acute pulmonary edema with normal and unchanged LVEF. The MVe' value is a key indicator of diastolic function because it reflects both relaxation and restoration forces [35]. It is commonly assumed that in the failing heart, MVe' is modified by diastolic pressure but is less load dependent than transmitral flow velocities [35]. However, AF changes the ventricular diastolic filling profile from double to single phase, leading to a significant increase of maximal MVe' velocity, falsely denotes a better LV diastolic function. The prevalence of $\mathrm{AF}$ in the survival and nonsurvival groups was similar; therefore, $\mathrm{AF}$ is not likely to be a factor affecting MVe' predictability of death in the present study group. It was demonstrated that early diastolic mitral annulus velocity in patients with LV systolic dysfunction and sinus rhythm was found to be a powerful predictor of cardiac mortality. Moreover, MVe' emerged as the best prognosticator for long-term follow-up and was even more accurate than the E/e' ratio, incremental to other clinical or echocardiographic variables in patients with impaired LV systolic function [36]. It was also reported that the presence of diastolic dysfunction provides important prognostic insights in patients with HF, especially preserved ejection fraction and sinus rhythm [36, 37]. According to available research, there is no published data concerning the prog- 
nostic impact of MVe' in AHF groups consisting of patients with preserved as well as reduced ejection fraction. However, further analysis of a larger mixed $\mathrm{HF}$ population with and without $\mathrm{AF}$ are needed to establish absolute predictive values separately for patients with $\mathrm{AF}$ and those with sinus rhythm.

\section{Limitations of the study}

The present study has several limitations.

Firstly, the study was performed at a single center with a small, retrospective sample size, which raises a concern of whether the sample is representative. However, demographic, clinical, and biological characteristics of the present study collectively correspond with the respective characteristics reported from other studies of AHF $[6,19]$.

Secondly, analysis of precise indices of iron metabolism, transfusion status or nutritional deficiency was not carried out.

Thirdly, analysis of TRPG was performed instead of a direct invasive pulmonary pressure estimation.

\section{Conclusions}

The present data demonstrates a novel relation between higher levels of RDW, elevated TRPG and elevated hsCRP values in patients with AHF. These findings suggest that RDW, the most important mortality predictor, is independently associated with elevated pulmonary pressure and systemic inflammation in patients with AHF. Moreover, more advanced age and a decreased MVe' are also independently associated with total mortality risk in AHF patients.

\section{Conflict of interest: None declared}

\section{References}

1. Roger VL. Epidemiology of heart failure. Circ Res. 2013; 113(6): 646-659, doi: 10.1161/CIRCRESAHA.113.300268, indexed in Pubmed: 23989710.

2. Patel K, Ferrucci L, Ershler W, et al. Red blood cell distribution width and the risk of death in middle-aged and older adults. Arch Intern Med. 2009; 169(5): 515, doi: 10.1001/archinternmed.2009.11.

3. Jo YH, Kim K, Lee JH, et al. Red cell distribution width is a prognostic factor in severe sepsis and septic shock. Am J Emerg Med. 2013; 31(3): 545-548, doi: 10.1016/j.ajem.2012.10.017, indexed in Pubmed: 23380094.

4. Scharte M, Fink MP. Red blood cell physiology in critical illness. Crit Care Med. 2003; 31(12 Suppl): S651-S657, doi:10.1097/01. CCM.0000098036.90796.ED, indexed in Pubmed: 14724462.
5. Dai Y, Konishi H, Takagi A, et al. Red cell distribution width predicts short- and long-term outcomes of acute congestive heart failure more effectively than hemoglobin. Exp Ther Med. 2014; 8(2): 600-606, doi: 10.3892/etm.2014.1755, indexed in Pubmed: 25009627.

6. Sotiropoulos K, Yerly P, Monney P, et al. Red cell distribution width and mortality in acute heart failure patients with preserved and reduced ejection fraction. ESC Heart Fail. 2016; 3(3): 198204, doi: 10.1002/ehf2.12091, indexed in Pubmed: 27818784.

7. Itani R, Minami Y, Haruki S, et al. Prognostic impact of disseminated intravascular coagulation score in acute heart failure patients referred to a cardiac intensive care unit: a retrospective cohort study. Heart Vessels. 2017; 32(7): 872-879, doi: 10.1007/ s00380-017-0946-y, indexed in Pubmed: 28120034.

8. van Kimmenade RRJ, Mohammed AA, Uthamalingam S, et al. Red blood cell distribution width and 1-year mortality in acute heart failure. Eur J Heart Fail. 2010; 12(2): 129-136, doi: 10.1093/ eurjhf/hfp179, indexed in Pubmed: 20026456.

9. Felker GM, Allen LA, Pocock SJ, et al. Red cell distribution width as a novel prognostic marker in heart failure: data from the CHARM Program and the Duke Databank. J Am Coll Cardiol. 2007; 50(1): 40-47, doi: 10.1016/j.jacc.2007.02.067, indexed in Pubmed: 17601544 .

10. Allen LA, Felker GM, Mehra MR, et al. Validation and potential mechanisms of red cell distribution width as a prognostic marker in heart failure. J Card Fail. 2010; 16: 230-238.

11. Bazick HS, Chang D, Mahadevappa K, et al. Red cell distribution width and all-cause mortality in critically ill patients. Crit Care Med. 2011; 39(8): 1913-1921, doi: 10.1097/ CCM.0b013e31821b85c6, indexed in Pubmed: 21532476.

12. Hampole CV, Mehrotra AK, Thenappan T, et al. Usefulness of red cell distribution width as a prognostic marker in pulmonary hypertension. Am J Cardiol. 2009; 104: 868-872.

13. Senthong V, Hudec T, Neale S, et al. Relation of red cell distribution width to left ventricular end-diastolic pressure and mortality in patients with and without heart failure. Am J Cardiol. 2017; 119(9): 1421-1427, doi: 10.1016/j.amjcard.2017.01.036, indexed in Pubmed: 28285713.

14. Oh J, Kang SM, Hong N, et al. Relation between red cell distribution width with echocardiographic parameters in patients with acute heart failure. J Card Fail. 2009; 15: 517-522.

15. Pascual-Figal DA, Bonaque JC, Redondo B, et al. Red blood cell distribution width predicts long-term outcome regardless of anaemia status in acute heart failure patients. Eur J Heart Fail. 2009; 11(9): 840-846, doi: 10.1093/eurjhf/hfp109, indexed in Pubmed: 19696056.

16. Aslan D, Gümrük F, Gürgey A, et al. Importance of RDW value in differential diagnosis of hypochrome anemias. Am J Hematol. 2002; 69(1): 31-33, indexed in Pubmed: 11835328.

17. Okonko DO, Mandal AKJ, Missouris CG, et al. Disordered iron homeostasis in chronic heart failure: prevalence, predictors, and relation to anemia, exercise capacity, and survival. J Am Coll Cardiol. 2011; 58(12): 1241-1251, doi: 10.1016/j.jacc.2011.04.040, indexed in Pubmed: 21903058.

18. Tkaczyszyn M, Comín-Colet J, Voors AA, et al. Iron deficiency and red cell indices in patients with heart failure. Eur J Heart Fail. 2018; 20(1): 114-122.

19. Makhoul BF, Khourieh A, Kaplan M, et al. Relation between changes in red cell distribution width and clinical outcomes in acute decompensated heart failure. Int J Cardiol. 2013; 167: 1412-1416. 
20. Weiss G, Goodnough LT. Anemia of chronic disease. N Engl J Med. 2005; 352(10): 1011-1023, doi: 10.1056/NEJMra041809, indexed in Pubmed:15758012.

21. Opasich C, Cazzola M, Scelsi L, et al. Blunted erythropoietin production and defective iron supply for erythropoiesis as major causes of anaemia in patients with chronic heart failure. Eur Heart J. 2005; 26(21): 2232-2237, doi: 10.1093/eurheartj/ehi388, indexed in Pubmed: 15987710.

22. Ganz T. Hepcidin, a key regulator of iron metabolism and mediator of anemia of inflammation. Blood. 2003; 102(3): 783-788, doi: 10.1182/blood-2003-03-0672.

23. Lippi G, Targher G, Montagnana M, et al. Relation between red blood cell distribution width and inflammatory biomarkers in a large cohort of unselected outpatients. Arch Pathol Lab Med. 2009; 133: 628-632.

24. Condon MR, Kim JE, Deitch EA, et al. Appearance of an erythrocyte population with decreased deformability and hemoglobin content following sepsis. Am J Physiol Heart Circ Physiol. 2003; 284(6): H2177-H2184, doi: 10.1152/ajpheart.01069.2002, indexed in Pubmed: 12742829.

25. Papageorgiou N, Tousoulis D, Androulakis E, et al. Inflammation and right ventricle: the hunting of the missing link. Int J Cardiol. 2013; 168(4): 3152-3154, doi: 10.1016/j.ijcard.2013.07.082, indexed in Pubmed: 23910446.

26. Pearson TA, Mensah GA, Alexander RW, et al. Markers of inflammation and cardiovascular disease: application to clinical and public health practice: A statement for healthcare professionals from the Centers for Disease Control and Prevention and the American Heart Association. Circulation. 2003; 107(3): 499-511, indexed in Pubmed: 12551878.

27. Lopes AA, Caramurú LH, Maeda NY. Endothelial dysfunction associated with chronic intravascular coagulation in secondary pulmonary hypertension. Clin Appl Thromb Hemost. 2002; 8(4): 353-358, indexed in Pubmed: 12516685.

28. Tandon HD, Kasturi J. Pulmonary vascular changes associated with isolated mitral stenosis in India. Br Heart J. 1975; 37(1): 26-36, indexed in Pubmed: 1111557.

29. Guazzi M, Naeije R. Pulmonary Hypertension in Heart Failure: Pathophysiology, Pathobiology, and Emerging Clinical Perspec- tives. J Am Coll Cardiol. 2017; 69(13): 1718-1734, doi: 10.1016/j. jacc.2017.01.051, indexed in Pubmed: 28359519.

30. Chen D, Assad-Kottner C, Orrego C, et al. Cytokines and acute heart failure. Crit Care Med. 2008; 36(1 Suppl): S9-S16, doi:10.1097/01.CCM.0000297160.48694.90, indexed in Pubmed: 18158483.

31. Costello ML, Mathieu-Costello O, West JB. Stress failure of alveolar epithelial cells studied by scanning electron microscopy. Am Rev Respir Dis. 1992; 145(6): 1446-1455, doi: 10.1164/ ajrccm/145.6.1446, indexed in Pubmed: 1596017.

32. Hu W, Jin R, Zhang J, et al. The critical roles of platelet activation and reduced NO bioavailability in fatal pulmonary arterial hypertension in a murine hemolysis model. Blood. 2010; 116(9): 1613-1622, doi: 10.1182/blood-2010-01-267112, indexed in Pubmed: 20511540.

33. Targonski R, Sadowski J, Cyganski PA. Impact of anticoagulation on the effectiveness of loop diuretics in heart failure with cardiorenal syndrome and venous thromboembolism. Blood Coagul Fibrinolysis. 2014; 25(2): 180-182, doi: 10.1097/MBC.0000000000000012, indexed in Pubmed: 24284867.

34. Gandhi SK, Powers JC, Nomeir AM, et al. The pathogenesis of acute pulmonary edema associated with hypertension. N Engl JMed. 2001; 344(1): 17-22, doi: 10.1056/NEJM200101043440103, indexed in Pubmed: 11136955.

35. Flachskampf FA, Biering-Sørensen T, Solomon SD, et al. Cardiac Imaging to Evaluate Left Ventricular Diastolic Function. JACC Cardiovasc Imaging. 2015; 8(9): 1071-1093, doi: 10.1016/j. jcmg.2015.07.004, indexed in Pubmed: 26381769.

36. Wang M, Yip G, Yu CM, et al. Independent and incremental prognostic value of early mitral annulus velocity in patients with impaired left ventricular systolic function. J Am Coll Cardiol. 2005; 45(2): 272-277, doi: 10.1016/j.jacc.2004.09.059, indexed in Pubmed: 15653027.

37. Zile MR, Gottdiener JS, Hetzel SJ, et al. Prevalence and significance of alterations in cardiac structure and function in patients with heart failure and a preserved ejection fraction. Circulation. 2011; 124(23): 2491-2501, doi: 10.1161/CIRCULATIONAHA.110.011031, indexed in Pubmed: 22064591. 